\title{
L'exploitation de l'hématite en Basse-Normandie durant la préhistoire récente
}

Projet collectif de recherche (2013)

Cyrille Billard, Xavier Savary, Lionel Dupret, Caroline Hamon et Guirec Querré

\author{
(2) OpenEdition \\ Journals \\ Édition électronique \\ URL : https://journals.openedition.org/adlfi/16823 \\ ISSN : 2114-0502 \\ Éditeur \\ Ministère de la Culture \\ Référence électronique \\ Cyrille Billard, Xavier Savary, Lionel Dupret, Caroline Hamon et Guirec Querré, «L'exploitation de \\ I'hématite en Basse-Normandie durant la préhistoire récente » [notice archéologique], ADLFI. \\ Archéologie de la France - Informations [En ligne], Normandie, mis en ligne le 15 mars 2016, consulté le \\ 09 juin 2021. URL : http://journals.openedition.org/adlfi/16823
}

Ce document a été généré automatiquement le 9 juin 2021.

(c) ministère de la Culture et de la Communication, CNRS 


\title{
L'exploitation de l'hématite en Basse-Normandie durant la préhistoire récente
}

Projet collectif de recherche (2013)

\author{
Cyrille Billard, Xavier Savary, Lionel Dupret, Caroline Hamon et Guirec \\ Querré
}

\section{NOTE DE L'ÉDITEUR}

Organisme porteur de l'opération : Ministère de la Culture

1 Les hématites oolithiques de type « oolithic ironstones » (OIS) définis par les géologues constituent l'une des sources de matériaux exploités pour la fabrication de colorant rouge au cours de la Préhistoire récente. Les gisements géologiques livrant ces matériaux sont bien connus en Basse-Normandie et ont été largement documentés à des fins d'exploitation minière. Leur origine géologique est plus facilement caractérisée que celles d'autres types d'hématite, dont la collecte peut provenir de gisements plus discrets et très ponctuels, ou même de simples encroûtements pédologiques. Intensément exploités aux périodes moderne et contemporaine, ces gisements de minerais de fer oolithiques sont aujourd'hui en grande partie épuisés en surface et ne constituent plus que de grandes cicatrices dans le paysage ou de longues galeries souterraines vides de roche. Pourtant les conditions d'affleurements et la couleur de ces roches ferrugineuses permettaient sans doute aux populations préhistoriques de les repérer facilement, selon leur position dans le paysage. La fouille récente du site de Colombelles a permis de mettre en lumière une exploitation d'hématite oolithique inédite pour le Néolithique ancien de Normandie, associée à une exploitation plus large d'autres matériaux locaux inscrits dans un vaste réseau d'échange (outils en silex, bracelets en schiste, perles en calcaire...). Le caractère nouveau de cette production d'objets liés à la fabrication de colorants a conduit à rechercher les caractéristiques de 
ces matériaux identifiés comme les minerais de fer oolithiques de type OIS, au regard d'autres gisements exploités aux frontières nord-orientales de la France (Belgique, Allemagne) et potentiellement incriminés dans des échanges à longues distances en Europe de l'Ouest.

2 Cet état des lieux a offert l'opportunité d'un programme collectif de recherche, centré sur la comparaison des corpus normands, belges et allemands, et qui ouvre des perspectives importantes quant à la diffusion de ce matériau en Europe de l'Ouest. Un protocole d'analyses a été mis en place à cet effet : macrophotographies des surfaces ; macroscopie ; microscopie (réalisation de lames minces au Service d'archéologie du département du Calvados); géochimie par analyse LA-ICP-MS (Field Museum à Chicago); diffractométrie de rayons $\mathrm{X}$ par analyse des minéraux argileux (agrégats orientés N-EG-Q500; labo MC2 de Caen) et par analyse en poudres désorientées de roche totale (au laboratoire du Service géologique de Belgique); analyses PIXE (Paris, C2RMF, accélérateur de particules du Grand Louvre et Liège); spectrométrie PXRF (analyseur portable de fluorescence X ; non destructif; Rennes, UMR 6566) et quelques tests de spectrographie RAMAN sur un unique échantillon.

3 L'ensemble de ces travaux a donné lieu à une table ronde qui s'est tenue près de Namur en Belgique en 2013, et qui est en cours de publication.

4 Au-delà de la comparaison entre régions productrices d'hématite oolithique, les principaux résultats montrent une bonne correspondance entre les matériaux géologiques locaux et le mobilier archéologique dans chacune des régions étudiées. Cette première présentation du corpus bas-normand a également permis de mettre en lumière l'exploitation d'un matériau, insoupçonnée jusqu'à présent. Elle laisse augurer de nouvelles découvertes maintenant que la communauté des prospecteurs a pris conscience des objets susceptibles d'être rencontrés. La découverte d'hématite travaillée sur les sites de la fin du Mésolithique ou du début du Néolithique peut impliquer des transferts culturels entre populations autochtones et colons néolithiques. Le site de Colombelles se trouve notamment au cœur d'une zone géographique riche en ressources minérales exploitées précocement et ayant donné lieu à des échanges à longue distance dès le début de la colonisation agricole : c'est le cas en particulier pour les silex jurassiques, le schiste, mais aussi la dolérite et les cornéennes. 


\section{INDEX}

\section{Année de l'opération : 2013}

nature https://ark.frantiq.fr/ark:/26678/crtqI2kNablQH

lieux https://ark.frantiq.fr/ark:/26678/pcrtSEeAipsBlD, https://ark.frantiq.fr/ark:/26678/ pcrt85PmfXV4X4, https://ark.frantiq.fr/ark:/26678/pcrtFGjgeNOvS6, https://ark.frantiq.fr/ark:/ 26678/pcrtMsSwEXeGIf

chronologie https://ark.frantiq.fr/ark:/26678/pcrtwpx5MU2hlw, https://ark.frantiq.fr/ark:/ 26678/pcrtNs85SfBRuH, https://ark.frantiq.fr/ark:/26678/pcrtH8P95EucZz

sujets https://ark.frantiq.fr/ark:/26678/pcrt8yYh5xgMeO, https://ark.frantiq.fr/ark:/26678/ pcrtJt3ZKiNEFK, https://ark.frantiq.fr/ark:/26678/pcrtuFMPNUEKWb

\section{AUTEURS}

\section{CYRILLE BILLARD}

Drac Basse-Normandie (service régional de l'archéologie) 